\title{
Investigation on the Dielectric, Physical and Chemical Properties of Palm Oil and Coconut Oil under Open Thermal Ageing Condition
}

\author{
Nur Aqilah Mohamad*, Norhafiz Azis ${ }^{\dagger}$, Jasronita Jasni*, Mohd Zainal Abidin Ab Kadir*, \\ Robiah Yunus**, Mohd Taufiq Ishak*** and Zaini Yaakub ${ }^{\S}$
}

\begin{abstract}
In this paper, a study is carried out to investigate the dielectric, physical and chemical properties of Palm Oil (PO) and Coconut Oil (CO) under open thermal ageing condition. The type of PO used in this study is Refined Bleached and Deodorized Palm Oil (RBDPO) Olein. The ageing experiment was carried out at $85^{\circ} \mathrm{C}$ and $115^{\circ} \mathrm{C}$ for $1,3,5,7$ and 14 days. Several parameters were measured such as $\mathrm{AC}$ breakdown voltage, dielectric dissipation factor, relative permittivity, resistivity, viscosity, moisture and acidity throughout the ageing duration. Based on the study, it is found that there are no significant changes on the $\mathrm{AC}$ breakdown voltages and relative permittivities for both RBDPO and CO. At ageing temperature of $115^{\circ} \mathrm{C}$, there are clear reduction trends of dielectric dissipation factor for $\mathrm{CO}$ and resistivities for most of RBDPO. On the other hand, no clear trends are observed for viscosities, moisture and acidities of RBDPO and $\mathrm{CO}$ throughout the ageing duration.
\end{abstract}

Keywords: Refined Bleach Deodorized Palm Oil, Coconut Oil, Open Thermal Ageing, Transformers

\section{Introduction}

Due to the increasing tight regulations on the environment and safety in recent years, alternative fluids such as vegetable oils are currently been considered for transformers application. Vegetable oils offer a suitable alternative for mineral oil since it is biodegradable, non-toxic, environment friendly and have high fire/flash points which ensure more in-service safety $[1,2]$.

Generally, vegetable oil also known as natural ester is made of triglyceride which consist of glycerol and fatty acids as shown in Fig. 1 [3, 4]. The fatty acids in triglycerides can determine the physical and chemical properties of vegetable oils such as viscosity, melting/pour points, oxidation stability and ageing characteristics [5]. For example, as the percentage of unsaturated fatty acids contents increase, the melting and pour points will decrease [6]. There were different types of vegetable oils that had been examined for application in transformers [1, 7-19].

Palm Oil (PO) and Coconut Oil (CO) are among the type of vegetable oils that are proposed as dielectric insulating fluids in transformers. Generally, there are 3 types of fluids that can be obtained from a palm nut which are Crude Palm

$\dagger \quad$ Corresponding Author: Centre for Electromagnetic and Lightning Protection Research(CELP), Universiti Putra Malaysia, 43400 UPM Serdang, Malaysia. (norhafiz@upm.edu.my)

* Centre for Electromagnetic and Lightning Protection Research (CELP), Universiti Putra Malaysia, 43400 UPM Serdang, Malaysia.

** Dept. of Chemical and Environmental Engineering, Universiti Putra Malaysia, 43400 UPM Serdang, Malaysia.

*** Dept. of Electrical and Electronic Engineering, Universiti Pertahanan Nasional Malaysia, 57000 UPNM Sungai Besi, Malaysia. Hyrax Oil Sdn. Bhd, Malaysia.

Received: January 19, 2015; Accepted: December 14, 2015<smiles>[R]C(=O)OCC(COC([R])=O)OC(=O)OCC</smiles>

Fig. 1. Triglyceride structure $[3,4]$.

Oil (CPO), Palm Kernel Oil (PKO) and Refined, Bleached, Deodorized Palm Oil (RBDPO) [12]. The most common $\mathrm{PO}$ considered for application in transformers is RBDPO [13-15]. RBDPO has an almost balance composition of saturated and unsaturated fatty acids while $\mathrm{CO}$ has a high percentage of saturated fatty acids.

Previously, a number of researches had been carried out on RBDPO and CO which cover on various aspects including the $\mathrm{AC}$ breakdown voltage, dielectric properties, viscosity, moisture and acidity [13, 15, 16-19]. Most of these studies mainly focus on its basic properties and there is still less information that can be obtained on the performance of RBDPO and CO especially under thermal ageing at different conditions.

Among the common ageing mechanisms of dielectric insulating fluids in transformers under normal loading are oxidation and hydrolysis [1, 20-22]. For vegetable oils, oxidation mainly involved with the double $\mathrm{C}=\mathrm{C}$ valence bonds within the triglyceride where the final by products of this mechanism includes aldehydes, ketones, alcohols and acids [23-25]. Hydrolysis of vegetable oils is initiated through interaction with water which will produce fatty acids as final by products $[1,25,26]$. 
Since the in-service failure could be costly, it is important to examine the thermal ageing performances of RBDPO and $\mathrm{CO}$ before it can be used for future application in transformers. In this paper, an examination on the dielectric, physical and chemical properties of RBDPO and CO aged under open condition are presented. The aim of the study is to examine the effect of presence of air on the properties of these oils under thermal ageing. Different parameters such as AC breakdown voltage, dielectric dissipation factor, relative permittivity, resistivity, viscosity, moisture and acidity were measured on the RBDPO and CO throughout the ageing duration.

\section{Experimental Descriptions}

\subsection{Fluids under test}

The type of PO used in this study was RBDPO Olein. In total, 5 samples of RBDPO and 1 sample of $\mathrm{CO}$ were investigated. Different RBDPO were used in this study due to the consideration on the fat and vitamin E/A contents. All samples were obtained from readily available cooking oil products in the market. Table 1 shows the composition of fats and vitamin E/A of these oils. The composition of saturated and unsaturated fats among the RBDPO are almost equal. There is a difference on the vitamin $\mathrm{E}$ contents where RBDPOE has the highest vitamin E followed by RBDPOD, RBDPOC, RDBPOB and RDBPOA. Only RBDPOA has vitamin A while $\mathrm{CO}$ mainly consists of saturated fat and has no either vitamin $\mathrm{E}$ or $\mathrm{A}$.

Table 1. Fat, vitamin E/A contents of all samples

\begin{tabular}{c|c|c|c|c|c}
\hline Samples & $\begin{array}{c}\text { S. fat } \\
(\mathrm{g})\end{array}$ & $\begin{array}{c}\text { P-U.S. fat } \\
(\mathrm{g})\end{array}$ & $\begin{array}{c}\text { M-U.S. fat } \\
(\mathrm{g})\end{array}$ & $\begin{array}{c}\text { V. E } \\
(\mathrm{mg})\end{array}$ & $\begin{array}{c}\text { V. A } \\
(\mu \mathrm{g})\end{array}$ \\
\hline RBDPOA & 45.4 & 11.6 & 43.0 & 4.4 & 264 \\
\hline RBDPOB & 44.4 & 12.2 & 43.3 & 50.0 & - \\
\hline RBDPOC & 44.3 & 12.1 & 43.6 & 56.0 & - \\
\hline RBDPOD & 43.0 & 12.0 & 45.0 & 60.0 & - \\
\hline RBDPOE & 43.0 & 14.0 & 43.0 & 75.0 & - \\
\hline CO & 92.8 & 3.6 & 3.6 & - & - \\
\hline
\end{tabular}

* S. fat $=$ Saturated fat, P-U.S. fat $=$ Polyunsaturated fat, M-U.S. fat $=$ Monounsaturated fat, V. E= Vitamin E, V. A= Vitamin A

\subsection{Thermal ageing procedure}

All samples were first pre-processed by filtering through a membrane filter with a pore size of $0.2 \mu \mathrm{m}$ and dried in an oven at $85{ }^{\circ} \mathrm{C}$ for 48 hours. The oven used for the thermal ageing has 2 sources of air intake. One of the valves is located at the bottom of the oven and remains open. The second valve at the back of the oven can be controlled and was kept closed in this study in order to reduce the intake of air from outside into the oven. The volume of each oil sample used for the ageing experiment was $500 \mathrm{ml}$. All samples were aged in glass bottles at $85^{\circ} \mathrm{C}$ and $115^{\circ} \mathrm{C}$ under open condition. The ageing durations of all samples for both temperatures were set to 1, 3, 5, 7 and 14 days respectively. All samples were rested further at ambient temperature for another 24 hours before tested for AC breakdown voltage, dielectric dissipation factor, relative permittivity, resistivity, viscosity, moisture and acidity.

\subsection{Test Descriptions}

\subsubsection{AC Breakdown Voltage}

The AC breakdown voltage measurement was conducted according to ASTM D 1816 by an automatic oil breakdown tester, BAUR DPA 75C at ambient temperature [27]. The test was carried out using VDE electrodes with a diameter of $36 \mathrm{~mm}$ facing each other where the gap distance between two electrodes was set to $1 \mathrm{~mm}$. The volume of the oil used for measurement was $400 \mathrm{ml}$ and the voltage ramping rate was set to $0.5 \mathrm{kV} / \mathrm{s}$. The time between breakdowns was set to 5 minutes. It was set longer than the recommended time in ASTM D 1816 in order to give time for expulsion of breakdown by products since vegetable oils such as RBDPO and CO have higher viscosities as compare to mineral oil $[28,29]$. In total, 50 measurements of AC breakdown voltages were obtained for each oil sample and average value was used in this study.

\subsubsection{Dielectric Dissipation Factor, Relative Permittivity and Resistivity}

Dielectric dissipation factor, relative permittivity and resistivity were measured according to IEC 60247 by a BAUR DTL C oil tester [30]. The test temperature was set to $90{ }^{\circ} \mathrm{C}$ and the volume of oil tested was $70 \mathrm{ml}$. Within the frequency range stated in IEC 60247, the dielectric dissipation factor, $\tan \delta$ can be calculated at frequency under interest using (1) [30].

$$
\tan \delta_{\mathrm{f} 1}=\tan \delta_{\mathrm{f} 2}\left(\mathrm{f}_{2} / \mathrm{f}_{1}\right)
$$

The relative permittivity, $\varepsilon_{\mathrm{x}}$ can be expressed based on simplified formula in (2) [30].

$$
\varepsilon_{\mathrm{x}}=\mathrm{C}_{\mathrm{x}} / \mathrm{C}_{\mathrm{a}}
$$

where $\mathrm{C}_{\mathrm{x}}$ is the capacitance of the cell filled with the liquid under test in farad and $\mathrm{C}_{\mathrm{a}}$ is the capacitance of the cell with air as the dielectric in farad. The resistivity, $\rho$ can be determined according to (3) [30].

$$
\rho=K(\mathrm{U} / \mathrm{I})
$$

where $\mathrm{K}$ is the cell constant in metre, $\mathrm{U}$ is the reading of the test voltage in volt and $\mathrm{I}$ is the reading of the current in ampere [30].

\subsubsection{Viscosity}

Viscosity was measured by an automatic SVM 3000 
Stabinger viscometer according to ASTM D 445 [31]. All samples were tested at $40{ }^{\circ} \mathrm{C}$ and the volume of the oil used for the measurement was $5 \mathrm{ml}$.

\subsubsection{Moisture}

The moisture measurement was carried out by a Metrohm 831 Karl Fisher (KF) Coulometer according to ASTM D 6304 [32]. The volume of the oil used for the measurement was $1 \mathrm{ml}$.

\subsubsection{Acidity}

Acidity was measured by a Metrohm 877 oil Titrano plus according to ASTM D 974 [33]. The weight of the oil used for the measurement was $10 \mathrm{~g}$.

\section{Dielectric Characteristics under Thermal Ageing}

\subsection{AC breakdown voltage}

There are no significant reductions of AC breakdown voltages for all samples at both ageing temperatures. At ageing temperature of $85^{\circ} \mathrm{C}$, all RBDPO show reduction

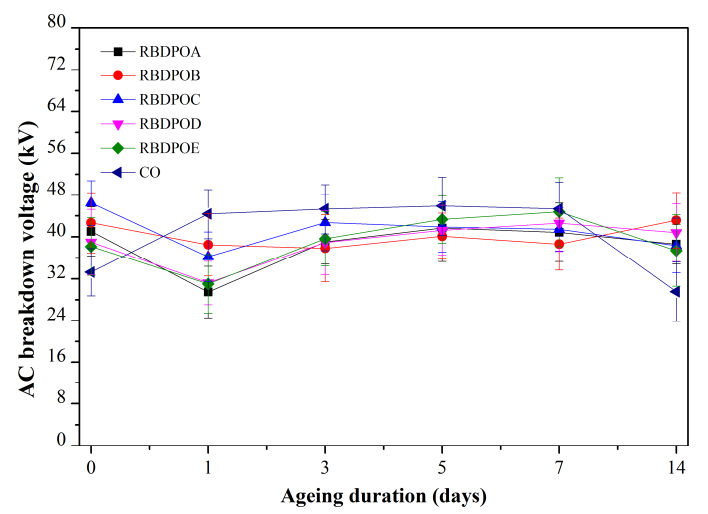

(a)

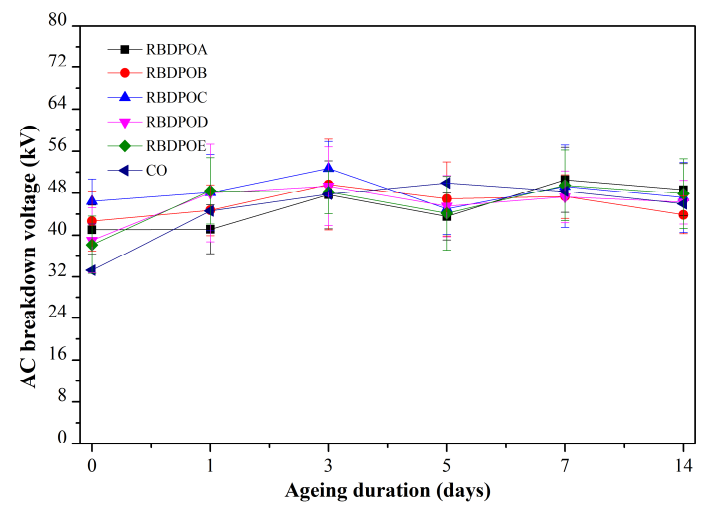

(b)

Fig. 2. Average AC breakdown voltages of all samples at (a) $85^{\circ} \mathrm{C}$, (b) $115^{\circ} \mathrm{C}$ of the AC breakdown voltages initially where the percentage of reduction is between $9.8 \%$ and $28.2 \%$ as shown in Fig. 2 a). The breakdown voltages of most of the RBDPO start to increase after 1 day of ageing. Meanwhile, $\mathrm{CO}$ shows an increment of $33.3 \%$ on the AC breakdown voltages immediately after the ageing is started. The AC breakdown voltages for most of all samples remain almost unchanged between 3 days and 7 days of ageing. Apart from RBDPOB, all samples show a reduction on the $\mathrm{AC}$ breakdown voltages after 7 days of ageing.

On the other hand, the patterns of $\mathrm{AC}$ breakdown voltages for all samples at ageing temperature of $115^{\circ} \mathrm{C}$ are slightly different from $85^{\circ} \mathrm{C}$ as seen in Fig. 2 b). Almost all samples show increment of AC breakdown voltages from start until 3 days of ageing. After 3 days of ageing, the AC breakdown voltages of all RBDPO slightly decrease with the percentage of decrement ranging between $5.4 \%$ and $14.6 \%$, while for $\mathrm{CO}$, it continues to slightly increase. The AC breakdown voltages for all samples start to fluctuate at values between $44 \mathrm{kV}$ and $53 \mathrm{kV}$ at the later stage of the ageing.

\subsection{Dielectric dissipation factor}

The dielectric dissipation factors of all RBDPO remain low even after 14 days of ageing at both ageing temperatures.

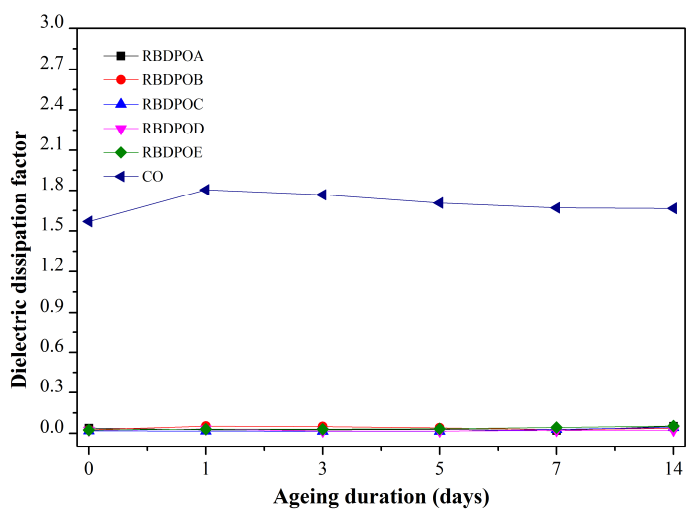

(a)

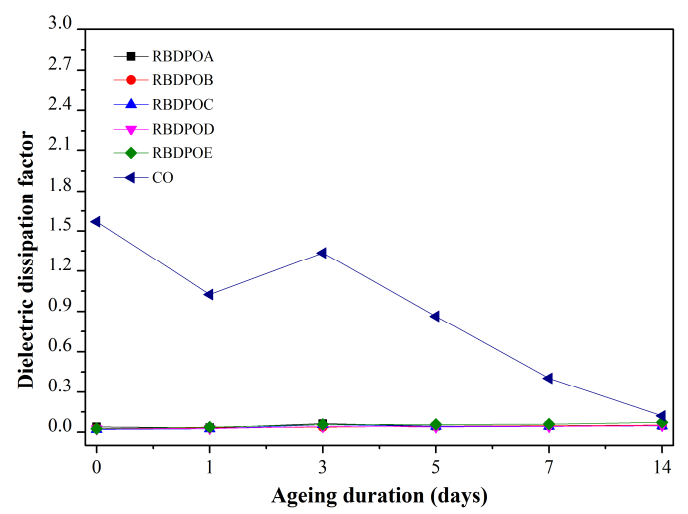

(b)

Fig. 3. Dielectric dissipation factors of all samples at (a) $85^{\circ} \mathrm{C}$, (b) $115^{\circ} \mathrm{C}$ 
At ageing temperature of $85^{\circ} \mathrm{C}$, the dielectric dissipation factors of all RBDPO are between 0.016 and 0.055 while at ageing temperature of $115^{\circ} \mathrm{C}$, the values are between 0.02 and 0.073 . The dielectric dissipation factor of $\mathrm{CO}$ remains the highest throughout the ageing duration at both ageing temperatures. At ageing temperature of $85^{\circ} \mathrm{C}$, the dielectric dissipation factor of $\mathrm{CO}$ slightly increases initially and later slightly decreases to 1.67 at the end of the ageing duration as shown in Fig. 3 a).

There is a clear reduction trend of dielectric dissipation factor for $\mathrm{CO}$ at ageing temperature of $115^{\circ} \mathrm{C}$ as shown in Fig. 3 b). The dielectric dissipation factor of $\mathrm{CO}$ decreases initially where the percentage of reduction is $34.5 \%$. It slightly increases after 1 day of ageing and decreases almost linearly close to the RBDPO values at the later stage of the ageing.

\subsection{Relative permittivity}

The relative permittivities of all samples remain almost unchanged throughout the ageing duration at both ageing temperatures as shown in Fig. 4. The range of relative permittivities of all RBDPO is between 2.79 and 2.86 at both ageing temperatures. The relative permittivity of $\mathrm{CO}$

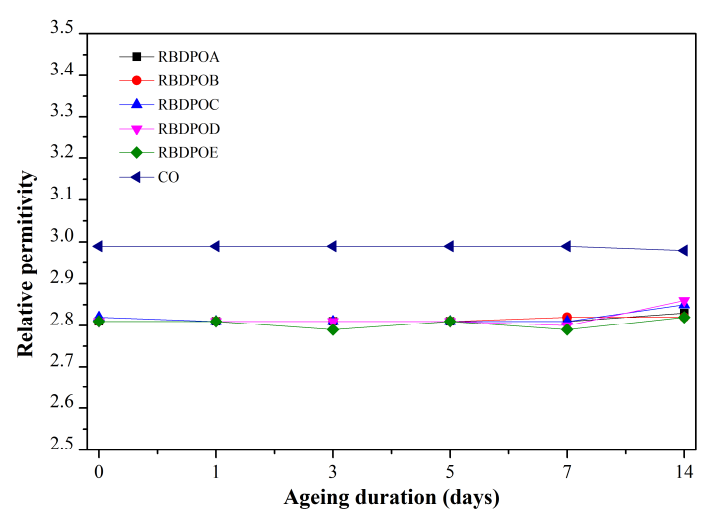

(a)

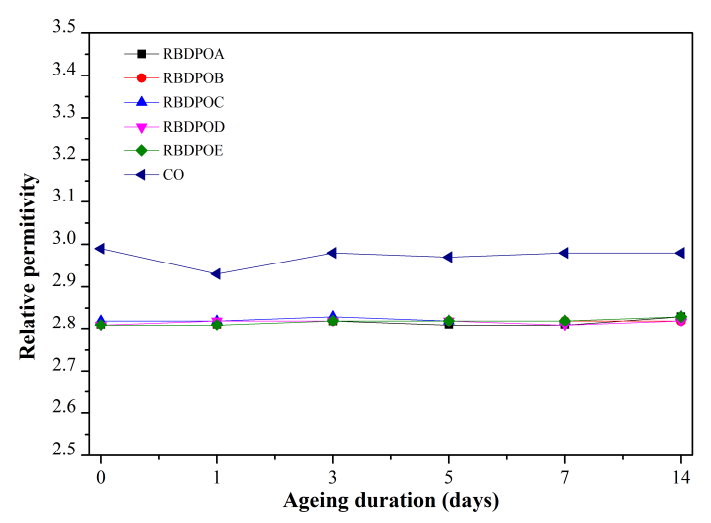

(b)

Fig. 4. Relative permittivities of all samples at (a) $85{ }^{\circ} \mathrm{C}$, (b) $115^{\circ} \mathrm{C}$ remains the highest throughout the ageing duration at both ageing temperatures with values ranging between 2.93 and 2.99 .

\subsection{Resistivity}

At ageing temperature of $85{ }^{\circ} \mathrm{C}$, most of the RBDPO show fluctuation of resistivities throughout the ageing duration. Only RBDPOC and RBDPOE show slight reduction trend of resistivities as seen in Fig. 5 a). On the other hand, the resistivity of $\mathrm{CO}$ remains lower than RBDPO throughout the ageing duration at values between $7.79 \times 10^{7} \Omega \mathrm{m}$ and $8.7 \times 10^{7} \Omega \mathrm{m}$.

The reduction trends of resistivities of all RBDPO are quite clear at ageing temperature of $115^{\circ} \mathrm{C}$ as seen in Fig. $5 \mathrm{~b}$ ). There are rapid reductions of resistivities for all RBDPO from start until 3 days of ageing and maintain at values ranging between $1.98 \times 10^{9} \Omega \mathrm{m}$ and $3.9 \times 10^{9} \Omega \mathrm{m}$ at the later stage of the ageing. The pattern of resistivity for $\mathrm{CO}$ is the same as at ageing temperature of $85^{\circ} \mathrm{C}$, where the value is much lower than all RBDPO. The resistivity of $\mathrm{CO}$ remains almost unchanged for the first 5 days of ageing. It starts to increase significantly after 5 days of ageing to a final value of $1.27 \times 10^{9} \Omega \mathrm{m}$.

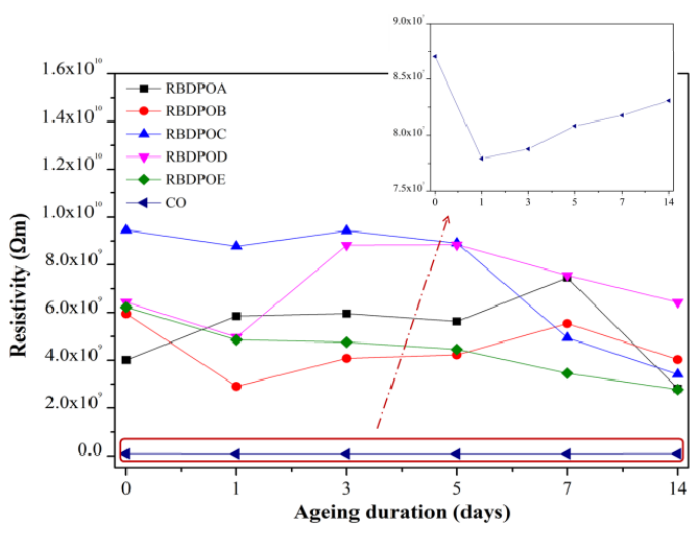

(a)

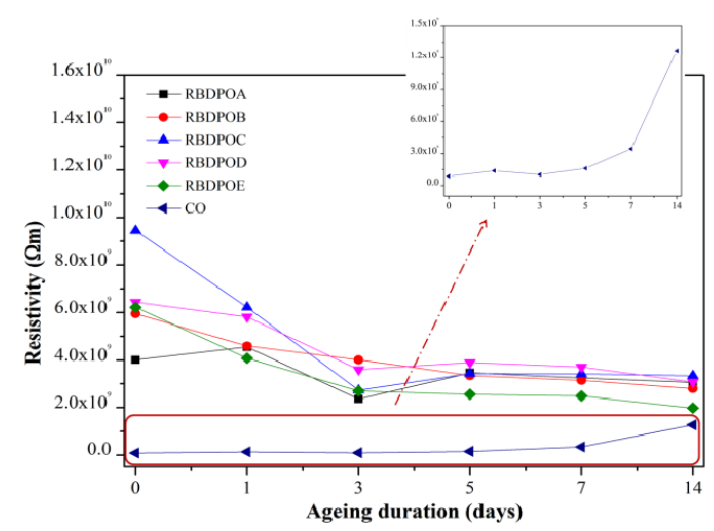

(b)

Fig. 5. Resistivities of all samples at (a) $85^{\circ} \mathrm{C}$, (b) $115^{\circ} \mathrm{C}$ 


\section{Physical and Chemical Characteristics under Thermal Ageing}

\subsection{Viscosity}

There is only a minor effect of ageing on the viscosities of all samples. The viscosity of $\mathrm{CO}$ remains almost unchanged and lower than all RBDPO throughout the ageing duration at both ageing temperatures at values ranging between $25.5 \mathrm{cSt}$ and $27 \mathrm{cSt}$. At ageing temperature of $85^{\circ} \mathrm{C}$, the viscosities of all RBDPO remain almost unchanged close to $40 \mathrm{cSt}$ from start until 5 days of ageing as shown in Fig. 6 a). After 5 days of ageing, the viscosities of all RBDPO start to fluctuate at values between $35.7 \mathrm{cSt}$ and $43.1 \mathrm{cSt}$.

The viscosities of RBDPOA, RBDPOD and RBDPOE samples remain stable throughout the ageing duration at ageing temperature of $115^{\circ} \mathrm{C}$ as seen in Fig. 6 b). On the other hand, the viscosities of RBDPOB and RBDPOC remain almost unchanged initially and start to slightly decrease after 3 days of ageing. After 5 days of ageing, the viscosities of RBDPOB and RBDPOC increase to final values of $41.1 \mathrm{cSt}$ and $42.8 \mathrm{cSt}$ respectively.-

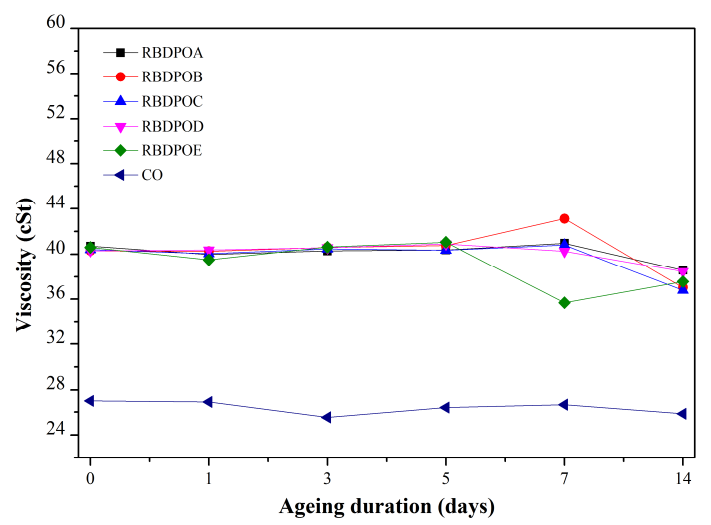

(a)

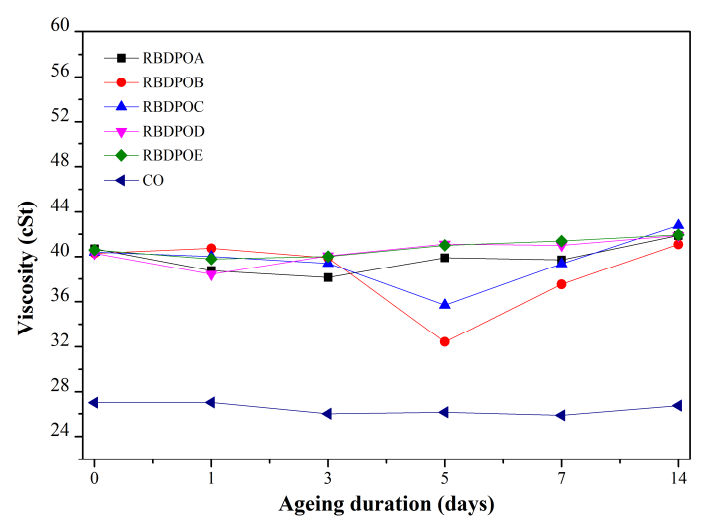

(b)

Fig. 6. Viscosities of all samples at (a) $85^{\circ} \mathrm{C}$, (b) $115^{\circ} \mathrm{C}$

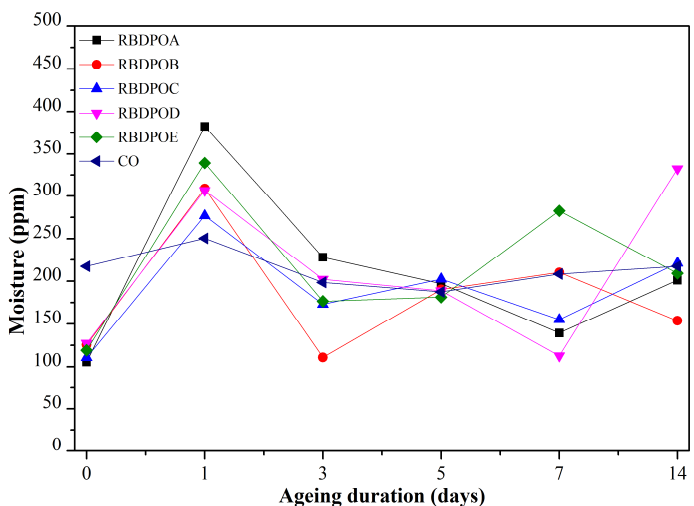

(a)

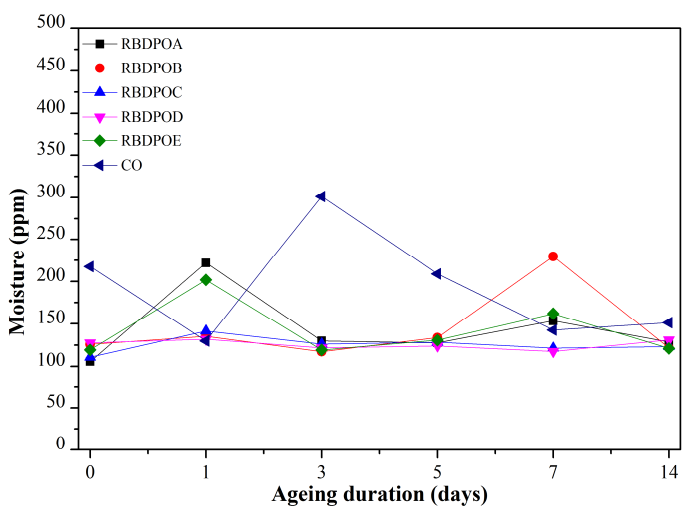

(b)

Fig. 7. Moisture of all samples at (a) $85^{\circ} \mathrm{C}$, (b) $115^{\circ} \mathrm{C}$

\subsection{Moisture}

There are no clear trends of moisture can be observed at both ageing temperatures. At ageing temperature of $85^{\circ} \mathrm{C}$, the moisture of all samples fluctuates at values between 106 ppm and 383 ppm as shown in Fig. 7 a).

While at ageing temperature of $115^{\circ} \mathrm{C}$, the moisture of RBDPOC and RBDPOD remain almost unchanged throughout the ageing duration at values between 111 ppm and $142 \mathrm{ppm}$ while for other samples, the moisture fluctuate at values between $106 \mathrm{ppm}$ and $301 \mathrm{ppm}$ as seen in Fig. 7 b).

\subsection{Acidity}

At ageing temperature of $85{ }^{\circ} \mathrm{C}$, the acidities of all RBDPO remain at low values between $0.001 \mathrm{mg} \mathrm{KOH} / \mathrm{g}$ and $0.004 \mathrm{mg} \mathrm{KOH} / \mathrm{g}$. $\mathrm{CO}$ has the highest acidity throughout the ageing duration ranging between $0.005 \mathrm{mg}$ $\mathrm{KOH} / \mathrm{g}$ and $0.013 \mathrm{mg} \mathrm{KOH} / \mathrm{g}$ as seen in Fig. $8 \mathrm{a}$ ).

At ageing temperature of $115{ }^{\circ} \mathrm{C}$, the acidities of RBDPOA, RBDPOD and RBDPOE remain low initially and start to slightly increase after 5 days and 7 days of ageing respectively. For other samples, the acidities fluctuate throughout the ageing duration at values less than $0.01 \mathrm{mg} \mathrm{KOH} / \mathrm{g}$ as shown in Fig. $8 \mathrm{~b}$ ). 


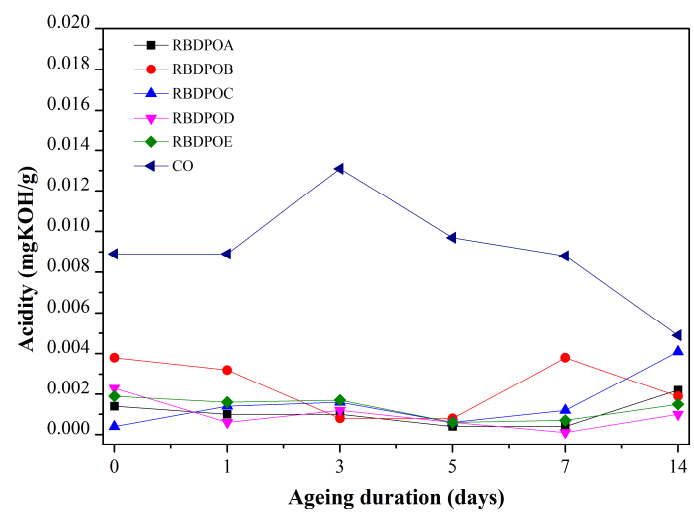

(a)

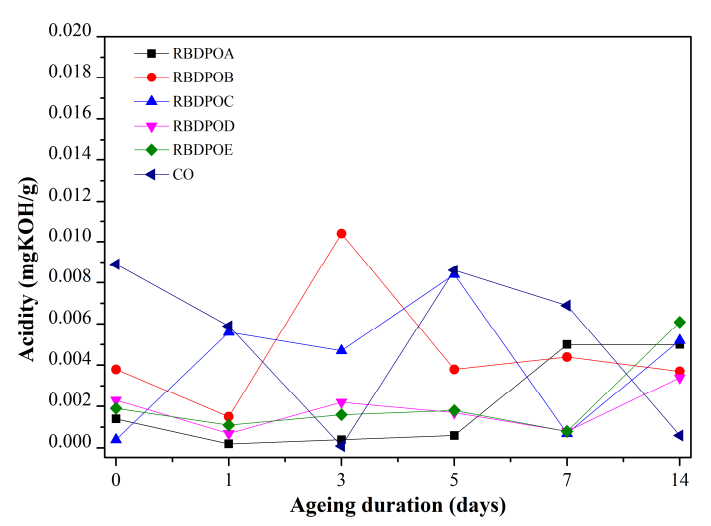

(b)

Fig. 8. Acidities of all samples at (a) $85^{\circ} \mathrm{C}$, (b) $115^{\circ} \mathrm{C}$

\section{Ageing Performance of RBDPO and CO under Open Condition}

Based on this study, it is found that the AC breakdown voltages of RBDPO and $\mathrm{CO}$ can still comply with the recommended limit for new, as-received vegetable oil suggested by ASTM D 6871 even after subjected to ageing [34]. The lowest AC breakdown voltages at both ageing temperatures for RBDPO and CO are $29.5 \mathrm{kV}$ and $29.6 \mathrm{kV}$ which are higher than the limit which is $\geq 20 \mathrm{kV}$ at $1 \mathrm{~mm}$ gap distance [34]. For dielectric dissipation factors, only RBDPOC and RBDPOD are within the recommended limit suggested by IEC 62770 which is $\leq 0.05$ at $90^{\circ} \mathrm{C}$. Most of other RBDPO samples exceed this value especially toward the end of the ageing duration. The dielectric dissipation factor of $\mathrm{CO}$ is much higher than the recommended limit of IEC 62770 throughout the ageing duration [35].

More importantly, it was found that under thermal ageing, the viscosities for RBDPO and $\mathrm{CO}$ under both ageing temperatures remain lower than the recommended limit suggested by ASTM D 6871 and IEC 62770, which is $\leq 50$ $\mathrm{mm}^{2} / \mathrm{s}$ at $40{ }^{\circ} \mathrm{C}[34,35]$. Acidities remain low where the highest values at both ageing temperatures for both RBDPO and $\mathrm{CO}$ are $0.0084 \mathrm{mg} \mathrm{KOH} / \mathrm{g}$ and $0.0131 \mathrm{mg} \mathrm{KOH} / \mathrm{g}$ respectively, which are well below the recommended limit of $\leq 0.06 \mathrm{mg} \mathrm{KOH} / \mathrm{g}$ suggested by ASTM D 6871 and IEC $62770[34,35]$. On the other hand, the highest moisture for $\mathrm{RBDPO}$ and CO throughout the ageing duration are 383 ppm and $301 \mathrm{ppm}$ respectively which are slightly higher than the recommended limit suggested by ASTM D 6871 and IEC 62770 which is $\leq 200$ ppm [34, 35].

It is also found that there are no significant differences on some of the dielectric, chemical and physical properties among the RBDPO. Only resistivity at ageing temperature of $85^{\circ} \mathrm{C}$ shows clear deviations among the RBDPO throughout the ageing duration. On the other hand, there are clear differences on the dielectric dissipation factor, relative permittivity, resistivity and viscosity between $\mathrm{RBDPO}$ and $\mathrm{CO}$ during the ageing duration. The difference of moisture for $\mathrm{CO}$ and $\mathrm{RBDPO}$ exist at 3 days and 5 days of ageing at temperature of $115^{\circ} \mathrm{C}$.

Oxygen is one of the main accelerators for oxidation of oil. Under current arrangement of accelerated thermal ageing, it is observed that the effect of oxidation is not significant on RBDPO and CO possibly due to the limited supply of oxygen resulted from the closure of the air valve at the back of the oven. This could be one of the reasons why there are no significant changes on some of the dielectric, physical and chemical properties of RBDPO and $\mathrm{CO}$ throughout the ageing duration. Further study will be carried out in the future to investigate the rate of oxidation of RBDPO and $\mathrm{CO}$ under different concentrations of oxygen and with the presence of copper and steel.

\section{Conclusion}

There is no significant effect of open ageing condition on the AC breakdown voltages of RBDPO and CO based on current arrangement of study. The dielectric dissipation factors of all RBDPO remain lower than CO throughout the ageing duration. There is a reduction trend of dielectric dissipation factor of $\mathrm{CO}$ especially at ageing temperature of $115{ }^{\circ} \mathrm{C}$. The relative permittivities of both RBDPO and $\mathrm{CO}$ remain almost unchanged throughout the ageing duration. There are clear reduction trends of resistivities for all RBDPO especially at ageing temperature of $115^{\circ} \mathrm{C}$ while the resistivity of $\mathrm{CO}$ remains lower than all $\mathrm{RBDPO}$ during the ageing duration.

In terms of physical and chemical properties, the viscosities of most of the RBDPO start to show slight changes after 3 and 5 days of ageing while the viscosity of $\mathrm{CO}$ remain almost unchanged throughout the ageing duration. There are no clear trends of moisture can be observed for both RBDPO and $\mathrm{CO}$ after subjected to ageing. In term of acidity, both of RBDPO and $\mathrm{CO}$ maintain at low values throughout the ageing duration and well below the suggested limit recommended in standards. 


\section{Acknowledgements}

The authors would like to thank Ministry of Education and Universiti Putra Malaysia for the funding under FRGS scheme (03-02-13-1280FR), (03-02-13-1279FR), PUTRA IPM and IPB schemes (GP-IPM/2013/9401500), (GPIPB/2014/9440801). Special thanks to Hyrax Oil Sdn. Bhd and Malaysia Transformer Manufacturing Sdn. Bhd. for the technical supports.

\section{References}

[1] S. Tenbohlen, M.Koch "Aging Performance and Moisture Solubility of Vegetable Oils for Power Transformer," IEEE Transactions on Power Delivery, vol. 25, no. 2, pp. 825-830, 2010.

[2] I. Khan, D. Martin, J. Dai and Z. D. Wang, "An Overview of the Suitability of Vegetable Oil Dielectrics for Use in Large Power Transformers," Euro TechCon, 2006.

[3] C. P. McShane, "Vegetable-Oil-Based Dielectric Coolants," in IEEE Industry Applications Magazine, vol. 8, no. 3, pp. 34-41, 2002.

[4] C. P. McShane, "Natural and Synthetic Ester Dielectric Fluids: Their Relative Environmental, Fire Safety, and Electrical Performance," Commercial Power Systems Technical Conference, pp. 1-8, 1999.

[5] J. Viertel, K. Ohlsson, and S. Singha, "Thermal Aging and Degradation of Thin Films of Natural Ester Dielectric Liquids," IEEE International Conference on Dielectric Liquids, 2011.

[6] A. A. Abdelmalik, "Chemically Modified Palm Kernel Oil Ester: A Possible Sustainable Alternative Insulating Fluid," Journal of Sustainable Materials and Technologies, 2014.

[7] Jian Li, S. Grzybowski, Yanfei Sun, Xiaoling Chen, "Dielectric Properties of Rapeseed Oil Paper Insulation," Annual Report Conference on Electrical Insulation and Dielectric Phenomena, pp. 500-503, 2007.

[8] Y. Bertrand, and L. C. Hoang, "Vegetable Oils as Substitute for Mineral Insulating Oils in MediumVoltage Equipments," in CIGRE, pp. 1-6, 2004.

[9] Olawuni Adeolu and Adejumobi I. A., "Breakdown Voltage Characteristics of Castor Oil as Alternative to Transformer Insulation Oil," International Journal of Scientific Engineering and Research (IJSER), vol. 2, no. 4, pp. 31-37, April 2014.

[10] Essam A. Al-Ammar, "Optical Observation of Streamer Propagation and Breakdown in Seed Based Insulating Oil under Impulse Voltages," International Journal of Physical Sciences, vol. 9, no. 13, pp. 292301, 16 July 2014.

[11] M. H. Abderrazzaq and F. Hijazi, "Impact of Multifiltration Process on the Properties of Olive Oil as a
Liquid Dielectric," IEEE Transactions on Dielectrics and Electrical Insulation, vol. 19, no. 5, pp. 16731680, October 2012.

[12] N. Azis, J. Jasni, M. Z. A. A. Kadir, and M. N. Mohtar, "Suitability of Palm Based Oil as Dielectric Insulating Fluid in Transformers," Journal of Electrical Engineering \& Technology, vol. 9, pp. 662-669, 2014.

[13] A. Rajab, A. S. S. Sudirham, and Suwarno, "A Comparison of Dielectric Properties of Palm Oil with Mineral and Synthetic Types Insulating Liquid under Temperature Variation," Inst. Technology Bandung J. Eng. Sci, vol. 43, pp. 191-208, 2011.

[14] U. U. Abdullahi, S. M. Bashi, R. Yunus, Mohibullah, and H. A. Nurdin, "The Potentials of Palm Oil as a Dielectric Fluid," Con-ference on National Power and Energy (PECon), pp. 224-228, 2004.

[15] S. S. Sinan, S. N. Shawaludin, J. Jasni, N. Azis, M. Z. A. Kadir, and M. N. Mohtar, "Investigation on the AC breakdown Voltage of RBDPO Olein," IEEE Innovative Smart Grid Technologies - Asia (ISGT Asia), pp. 760-763, 20-23 May 2014.

[16] K. Kiasatina, M. Kamarol, M. Zulhilmey, and Y. A. Arief, "Breakdown Characteristics of RBDPO and Soybean Oil Mixture for Transformer Application," International Conference on Electrical, Control and Computer Engineering (INECCE), pp. 219-222, 2122 June 2011.

[17] M. Y. Yusnida, M. Kamarol, and M. A. Ahmad, "Breakdown Voltage Characteristic of MO and RBDPO Mixture for Power Transformer Insulation," IEEE Colloquium on Humanities, Science and Engineering (CHUSER), pp. 300-303, 3-4 December 2012.

[18] Suwarno and S. Aditama, "Dielectric Properties of Palm Oils as Liquid Insulating Materials: Effects of Fat Content," International Symposium on Electrical Insulating Materials (ISEIM), vol. 1, pp. 91-94, 5-9 June 2005

[19] Suwarno, F. Sitinjak, I. Suhariadi, and L. Imsak, "Study on the Characteristics of Palm Oil and its Derivatives as Liquid Insulating Materials," International Conference on Properties and Applications of Dielectric Materials (ICPADM), vol. 2, pp. 495498, 1-5 June 2003.

[20] K. B. Liland, M. Kes, M.-H. G. Ese, L. E. Lundgaard, and B. E. Christensen, "Study of Oxidation and Hydrolysis of Oil Impregnated Paper Insulation for Transformers using a Microcalorimeter," IEEE Transactions on Dielectrics and Electrical Insulation, vol. 18, no. 2, pp. 2059-2068, 2011.

[21] L. E. Lundgaard, W. Hansen, and S. Ingebrigtsen, "Ageing of Mineral Oil Impregnated Cellulose by Acid Catalysis," IEEE Transactions on Dielectrics and Electrical Insulation, vol. 15, no. 2, pp. 540-546, 2008. 
[22] I. Fofana, J. S. N'cho, J. C. Olivares-Galvan, R. E. Perez, and P. S. Georgilakis, "Comparative Studies of the Stabilities to Oxidation and Electrical Discharge between Ester Fluids and Transformer Oils," IEEE North American Power Symposium (NAPS), pp. 1-4, 2011.

[23] "Experiences in Service with New Insulating Liquids," CIGRE Brochure 436, 2010.

[24] E. Sherwin, "Oxidation and Antioxidants in Fat and Oil Processing," Journal of the American Oil Chemists' Society, vol. 55, pp. 809-814, 1978.

[25] H. M. Wilhelm, L. Tulio, R. Jasinski, and G. Almeida, "Aging Markers for In-service Natural Ester-based Insulating Fluids," IEEE Transactions on Dielectrics and Electrical Insulation, vol. 18, No. 3, pp. 714-719, 2011.

[26] D. Rooney and L. R. Weatherley, "The Effect of Reaction Conditions upon Lipase Catalysed Hydrolysis of High Oleate Sunflower Oil in a Stirred Liquid - Liquid Reactor," Process Biochemistry, vol. 36, pp. 947-953, 2001.

[27] ASTM D 1816, "Standard Test Method for Dielectric Breakdown Voltage of Insulating Liquids using VDE Electrodes."

[28] IEEE Std C57.147, "IEEE Guide for Acceptance and Maintenance of Natural Ester Fluids in Transformers," IEEE Power \& Energy Society, 2008.

[29] X. Wang and Z. D. Wang, "Study of Dielectric Behavior of Ester Transformer Liquids under AC Voltage," in IEEE Transactions on Dielectrics and Electrical Insulation, vol. 19, no. 6, pp. 1916-1925, December 2012.

[30] IEC 60247, "Measurement of Relative Permittivity, Dielectric Dissipation Factor and D.C. Resistivity of Insulating Liquids."

[31] ASTM D 445, "Standard Method of Test for Viscosity of Transparent and Opaque Liquids (Kinematic and Dynamic Viscosities)."

[32] ASTM D 6304, "Standard Test Method for Determination of Water in Petroleum Products, Lubricating Oils and Additives by Coulometric Karl Fisher Titration."

[33] ASTM D 974, "Standard Test Method for Acid and Base Number by Color-Indicator Titration."

[34] ASTM D 6871, "Standard Specification for Natural (Vegetable Oil) Ester Fluids Used in Electrical Apparatus," 2008.

[35] IEC 62770, "Fluids for Electrotechnical Applications - Unused Natural Esters for Transformers and Similar Electrical Equipment," 2013.

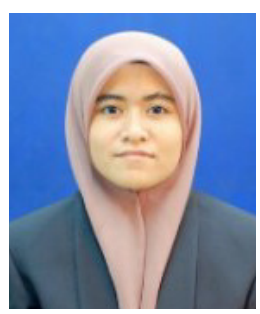

Nur Aqilah Mohamad received B. Eng degree in Electrical and Electronic Engineering (Power) (2013) from Universiti Pertahanan Nasional Malaysia. Currently she is studying for her M. Sc Degree in Master of Science in the Department of Electrical and Electronic Engineering, University of Putra

Malaysia.

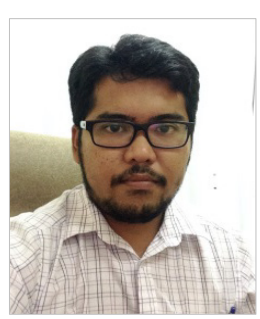

Norhafiz Azis received B. Eng degree in Electrical and Electronic Engineering (2007) from Universiti Putra Malaysia and PhD degree in Electrical Power Engineering (2012) from The University of Manchester in UK. Currently he is a Senior Lecturer at the Department of Electrical and Electronic Engineering, Universiti Putra Malaysia, Malaysia. His research interests are in-service ageing of transformer insulation, condition monitoring, asset management and alternative insulation materials for transformers.

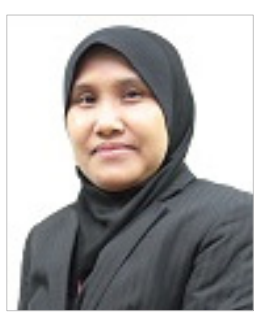

Jasronita Jasni received B. Eng degree in Electrical Engineering (1998) and M. Eng. in Electrical Engineering (2001) from Universiti Teknologi Malaysia. She received the $\mathrm{PhD}$ degree in Electrical Power Engineering from Universiti Putra Malaysia in 2010. Currently she is a Senior Lecturer in the Department of Electrical and Electronic Engineering, Universiti Putra Malaysia, Malaysia. She is an IEEE member. Her research interests include power system analysis for static and dynamics, load flow analysis, embedded generation and renewable energy.

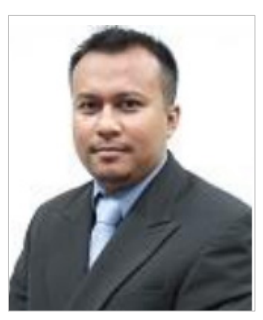

Mohd Zainal Abidin Ab Kadir received the B. Eng degree in Electrical and Electronic Engineering from Universiti Putra Malaysia in 2000 and $\mathrm{PhD}$ degree in High Voltage Engineering (2006) from The Universiti of Manchester in UK. Currently, he is a Professor in the Department of Electrical and Electronics Engineering, Faculty of Engineering, University Putra Malaysia. His research interests include high voltage engineering, insulation coordination, lightning protection, EMC/EMI, kerauna-medicine and power system transients. 


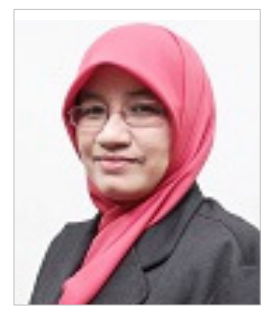

Robiah Yunus received the B. Eng degree in Chemical Engineering (1986) from University Alabama in USA and M. Eng. in Integrated Design of Chemical Plant (1989) from University of Leeds, UK. She received the $\mathrm{PhD}$ degree in Chemical Engineering from Universiti Putra Malaysia in 2003.

Currently she is a Professor in the Department of Chemical Engineering, Universiti Putra Malaysia. Her research interests are renewable energy, reaction engineering and process engineering.

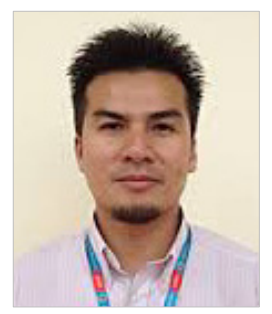

Mohd Taufiq Ishak received the B. Eng degree in Electrical Engineering (2002) from Universiti Tenaga Nasional in Malaysia and M. Eng. in Electrical Engineering (2004) from UMIST, UK. $\mathrm{He}$ received the $\mathrm{PhD}$ degree in Electrical Power Engineering from University of Manchester, UK in 2010.

Currently he is a Senior Lecturer in the Department of Electrical and Electronic Engineering, Universiti Pertahanan Nasional Malaysia. His research interests are high voltage, power transformer, asset management, lifetime prediction, renewable energy, conditioning monitoring and smart grid.

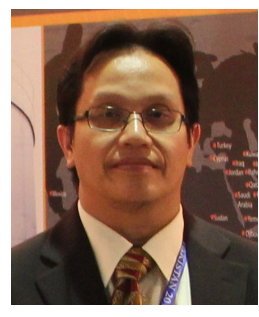

Zaini Yaakub received the degree of Applied Chemistry with Honours from Sheffield Hallam University, United Kingdom in 1993. He joined Caleb Brett Malaysia in the same year as a chemist before joining Hyrax Oil in 1994. Currently, he is an Assistant General Manager at Hyrax Oil after having had a working experience for more than 20 years on various responsibilities and roles. His research interests are in the field of electrical insulating oils and currently doing his Ph.D degree at UPM. 